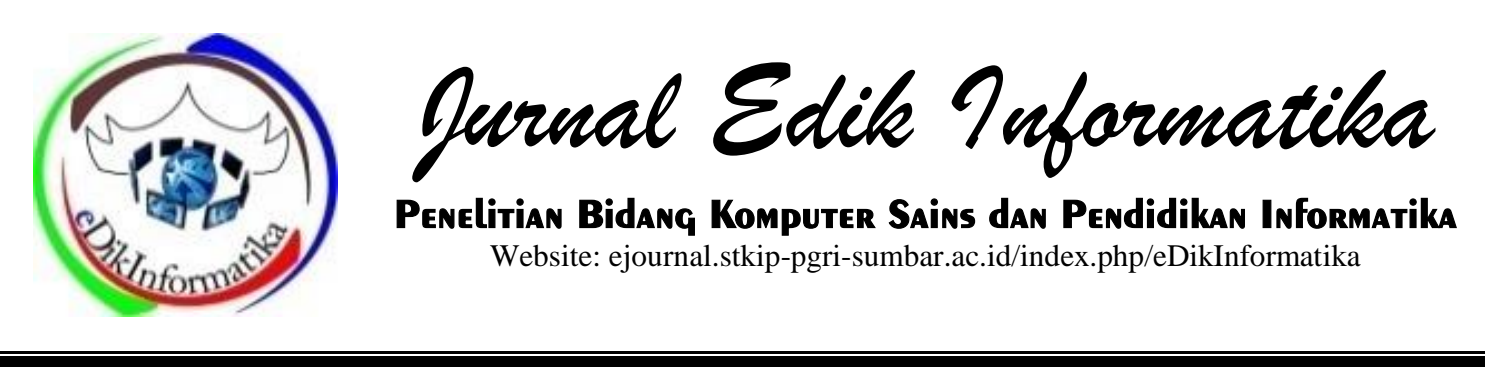

\title{
ALGORITMA ASOSIASI UNTUK MENDAPATKAN POLA MATA KULIAH PILIHAN STIE-GK MUARA BULIAN
}

Azwar Anas', Budi Darma ${ }^{2}$

${ }^{1,2}$ STIE-GK Muara Bulian

azwarzayn@gmail.com,91bdarma@gmail.com

\section{INFO ARTIKEL}

\section{Diterima:}

06 Juli 2019

Direview:

29 Juli 2019

Disetujui:

08 Oktober 2019

Keywords:

Algorithm, Apriori,

Data Mining, Courses.

\begin{abstract}
This research is motivated by the number of data collection piles of electives of STIE-GK Muara Bulian students from year to year. The pile of data only becomes junk data if it is not managed properly. Therefore, the authors conducted this research, the authors used the association algorithm to get the pattern of taking courses of choice for STIE-GK students Muara Bulian. The task of data mining is to produce all the rules of association in a transactional table, which has a support value of more than the minimum support. The rule must also have support that is greater than confidence. As for testing the algorithm, the author uses Orange data mining software. The final result of this study is a description of the pattern of taking elective courses that most often occur simultaneously. Based on the discussion in this study, the value of support and confidence with the 2-itemet reference that has the highest value is a combination of Marketing and SKB with $14 \%$ support and $18 \%$ confidence. Whereas for the 3 -itemset reference, there are 4 association rules that meet the minimum support and minimum confidence requirements. It was found that all combinations of the elective courses of Marketing, SKB and HRM had the highest scores, namely $12 \%$ support and $85 \%$ confidence.
\end{abstract}

\section{PENDAHULUAN}

Tugas pokok perguruan tinggi adalah Pendidikan dan pengajaran, Penelitian dan Pengabdian kepada Masyarakat yang tertuang dalam Tri Darma Perguruan Tinggi. Begitu pula mahasiswa, salah satu tugas utamanya adalah malaksanakan pendidikan. Pendidikan yang ditempuh oleh mahasiswa tertuang dalam bentuk mata kuliah. Mata kuliah diukur dalam satuan kredit semester. Mata kuliah yang ditawarkan oleh perguruan tinggi dibagi pula dalam beberapa kategori. Misalnya mata kuliah wajib nasional, mata kuliah wajib institusi dan mata kuliah pilihan. Mata kuliah wajib tentu saja harus diambil oleh mahasiswa, sedangkan mata kuliah pilihan adalah mata kuliah optional yang hanya wajib diambil sebagiannya.

Sesuai dengan tuntutan perubahan zaman dan kebutuhan masyarakat, setiap perguruan tinggi dituntut untuk menawarkan berbagai jurusan. Bahkan 
setiap jurusan juga dituntut untuk menawarkan berbagai konsentrasi yang didukung oleh mata kuliah konsentrasi. STIE-Graha Karya Muara Bulian saat ini memiliki dua jurusan, yaitu $\mathrm{S} 1$ Manajemen dan D3 Akuntansi. Jurusan Manajemen memiliki 3 konsentrasi, yaitu Pemasaran, MSDM dan Syari'ah. Sedangkan jurusan Akuntansi memiliki konsentrasi Akuntansi SKB Daerah dan Akuntansi SKB Perusahaan. Mata kuliah pilihan akan ditawarkan pada semester tiga pada setiap jurusan.

Tingginya jumlah mahasiswa akan berdampak pada banyaknya aktivitas pengambilan mata kuliah pilihan yang beragam pada setiap mahasiswa tersebut. Adakalanya mata kuliah pilihan yang ditawarkan kepada mahasiswa ternyata tidak efektif. Misalnya ada mata kuliah yang kurang diminati oleh mahasiswa dengan berbagai alasan dan pertimbangan. Untuk melakukan analisis terhadap hal ini, dengan cara manual tentu saja akan memakan waktu yang lama dan kurang akurat dalam pengambilan kesimpulan. Tumpukan berkas Kartu Rencana Studi (KRS) dari semester ke semester per mahasiswa tentu saja sangat banyak. Sementara pengambil kebijakan dalam hal ini pengelola jurusan, perlu mempertimbangkan mata kuliah yang kurang diminati tersebut untuk diganti atau dicarikan solusi lainnya.

Sehubungan dengan hal tersebut, penulis akan menawarkan sistem berbasis komputer untuk melakukan analisis dan menadapatkan pola terhadap mata kuliah pilihan pada STIE-Graha Karya Muara Bulian. Oleh karena itu dalam penelitian ini, peneliti akan menggunakan algoritma apriori dan menggunakan software Orange untuk melakukan uji coba terhadap hasil analisis tersebut.

Algoritma aprioritermasuk jenis aturan asosiasi pada data mining. Selain apriori, yang termasuk dalam golongan ini adalah metode Generalized Rule Induction dan Algoritma Hash Based. Aturan yang menyatakan asosiasi antara beberapa atribut sering disebut affinity analysis atau market basket analysis.

Tugas dari data miningadalah untuk menghasilkan semua kaidah asosiasi pada suatu tabel transaksional, yang mempunyai nilai support lebih dari minimum support. Kaidah tersebut juga harus mempunyai support yang lebih besar dari confidence.

\section{METODE PENELITIAN}

Setiap melakukan sebuah penelitian, tentu harus berdasarkan metode penelitian yang benar sehingga dapat mempermudah jalannya penelitian tersebut. Metode penelitian merupakan kerangka kerja dalam melakukan penelitian. Sesuai dengan kerangka kerja tersebut maka penelitian yang dilakukan akan berjalan dengan sistematis dan memberikan hasil yang baik.

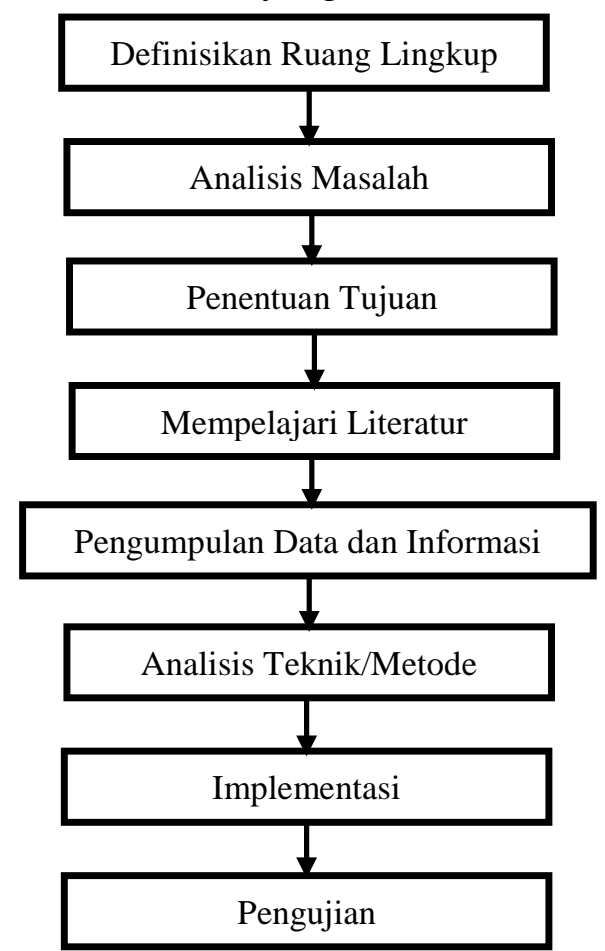

Gambar 1. Kerangka Kerja Penelitian

Pada bagian ini akan diuraikan kerangka penelitian, kerangka ini merupakan langkah-langkah yang akan 
dilakukan dalam penyelesaian masalah yang akan dibahas. Langkahnya diuraikan seperti berikut ini:

1. Mendefinisikan Ruang Lingkup Masalah

Ruang lingkup masalah yang akan diteliti harus ditentukan terlebih dahulu, karena tanpa mampu menentukan serta mendefinisikan batasan masalah yang akan diteliti, maka tidak akan pernah didapat suatu solusi yang terbaik dari masalah tersebut. Jadi langkah pertama ini adalah langkah awal yang terpenting dalam penulisan ini.

2. Analisis Masalah

Langkah analisis masalah adalah untuk dapat memahami masalah yang telah ditentukan ruang lingkup atau batasannya. Dengan menganalisa masalah yang telah ditentukan tersebut, maka diharapkan masalah dapat dipahami dengan baik. Pada bagian ini digambarkan proses untuk mendapatkan pola pengambilan mata kuliah pilihan dengan menggunakan algoritma apriori. Selain itu juga diuraikan tentang kebutuhan data untuk menggali kaidah asosiasi mata kuliah pilihan. Berdasarkan hasil analisis tersebut, maka algoritma apriori hendaknya mampu mendapatkan pola pengambilan mata kuliah pilihan dengan baik.

3. Penentuan Tujuan

Berdasarkan pemahaman dari masalah, maka ditentukan tujuan yang akan dicapai dari penulisan ini. Pada tujuan ini ditentukan target yang dicapai, terutama yang dapat mengatasi masalah-masalah yang ada.

4. Mempelajari Literatur

Literatur digunakan untuk mencapai tujuan, maka dipelajari berbagai literatur yang relevan dengan masalah yang diteliti. Kemudian literatur-literatur yang dipelajari tersebut diseleksi untuk dapat ditentukan literatur-literatur mana yang akan digunakan dalam penelitian.

Literatur diambil dari internet, yang berupa artikel dan jurnal ilmiah tentang data mining, association rule dan algoritma apriori, serta bahan bacaan lain yang mendukung penelitian.

5. Pengumpulan Data dan Informasi Pengumpulan data dilakukan dengan observasi yaitu pengamatan secara langsung di tempat penelitian sehingga permasalahan yang ada dapat diketahui dengan jelas. Kemudian dilakukan interview yang bertujuan untuk mendapatkan informasi atau data yang dibutuhkan. Selain itu juga dilakukan studi kepustakaan yaitu dengan membaca buku-buku yang menunjang dalam melakukan analisa terhadap data dan informasi yang didapat.

Adapun data-data yang diperlukan dalam penelitian ini adalah data Kartu Rencana Studi mahasiswa STIE-GK Muara Bulian yang memuat data mata kuliah pilihan.

6. Analisis Teknik/Metode yang digunakan

Bagian ini bertujuan untuk menganalisis dan memahami teknik yang akan digunakan dalam pengolahan data yang telah diperoleh dari tempat penelitian, terutama pada proses, yang mana teknik yang digunakan untuk pengolahan data dengan algoritma apriori.

7. Implementasi

Setelah dilakukan analisis teknik yang digunakan, maka dilakukan implementasi terhadap software dalam hal ini adalah software data mining Orange. Tentu saja penerapan analisis pada software tersebut menggunakan algoritma 
apriori. Jika penerapan sistem sudah berjalan dengan lancar dan akurat, maka sistem dapat diimplementasikan sesuai dengan kebutuhan.

8. Pengujian

Pengujian dilakukan untuk mendapatkan hasil yang sesuai dengan melakukan perbandingan antara perhitungan manual dan komputerisasi, berikut ini langkahlangkah pengujian yang akan dilakukan:

a. Melakukan pengujian algoritma apriori terhadap data pengajuan mata kuliah pilihan secara manual.

b. Setelah dilakukan perhitungan manual, selanjutnya dilakukan perhitungan menggunakan software data mining Orange dengan memasukkan data-data dan diproses menggunakan aturan asosiasi.

c. Tahap terakhir adalah melakukan perbandingan antara perhitungan manual dengan komputerisasi, jika hasil yang dicapai sama atau hampir sama, maka data yang diproses dan teknik yang digunakan telah benar.

HASIL DAN PEMBAHASAN

Analisis Asosiasi dengan Algoritma Apriori

Penelitian ini, penulis hanya melakukan analisis terhadap 50 mahasiswa yang mengambil mata kuliah pilihan. Mahasiswa yang diamati adalah mahasiswa pada jurusan manajemen sesuai dengan konsentrasi masingmasing.

Algoritma dalam menentukan pola pengajuan mata kuliah pilihan mahasiswa adalah algoritma apriori untuk melakukan analisanya. Data-data judul yang telah dikumpulkan akan diolah menggunakan prinsip kerja algoritma apriori yang mampu memecahkan data bersifat frequent itemset atau mencari pola berulang.

Aturan asosiasi biasanya dinyatakan dalam bentuk:

$\{$ MMSDM, SKB $\} \rightarrow$ \{Pemasaran $\}$ $\{$ support $=40 \%$, confidence $=50 \%\}$

Artinya 50\% dari kegiatan pengambilan mata kuliah MSDM dan SKB juga memuat Pemasaran. Sementara $40 \%$ dari seluruh pengambilan mata kuliah yang ada memuat ketiga item tersebut.

\section{Menentukan Variabel}

Data yang akan diolah dalam menentukan pola pengambilan mata kuliah ini adalah data mata kuliah pilihan mahasiswa STIE-GK. Adapun variabelvariabel data pengajuan judul yang akan diolah adalah:

1. Mahasiswa

2. Mata kuliah 1

3. Mata kuliah 2

4. Mata kuliah 3

Berdasarkan variabel-variabel di atas, mahasiswa akan dibagi kedalam beberapa kelompok berdasarkan jenis mata kuliah yang sama, hal ini dilakukan agar proses analisa data dapat dilakukan dengan mudah menggunakan algoritma apriori.

Tabel 1. Data Mata Kuliah Pilihan

\begin{tabular}{|c|l|l|l|}
\hline Mhs & \multicolumn{1}{|c|}{ MK1 } & \multicolumn{1}{|c|}{ MK2 } & MK3 \\
\hline 1 & SKB & Pemasaran & MSDM \\
\hline 2 & MSDM & & \\
\hline 3 & Pemasaran & SKB & \\
\hline 4 & Pemasaran & MSDM & SKB \\
\hline 5 & SKB & Pemasaran & \\
\hline 6 & MSDM & SKB & Pemasaran \\
\hline 7 & Pemasaran & SKB & MSDM \\
\hline 8 & MSDM & Pemasaran & \\
\hline
\end{tabular}




\begin{tabular}{|c|c|c|c|}
\hline Mhs & MK1 & MK2 & MK3 \\
\hline 9 & SKB & MSDM & \\
\hline 10 & Pemasaran & MSDM & SKB \\
\hline 11 & Pemasaran & MSDM & SKB \\
\hline 12 & SKB & Pemasaran & \\
\hline 13 & MSDM & SKB & Pemasaran \\
\hline 14 & Pemasaran & SKB & MSDM \\
\hline 15 & MSDM & Pemasaran & \\
\hline 16 & SKB & Pemasaran & \\
\hline 17 & MSDM & SKB & Pemasaran \\
\hline 18 & Pemasaran & SKB & MSDM \\
\hline 19 & MSDM & Pemasaran & \\
\hline 20 & SKB & MSDM & \\
\hline 21 & Pemasaran & MSDM & SKB \\
\hline 22 & Pemasaran & MSDM & SKB \\
\hline 23 & SKB & Pemasaran & MSDM \\
\hline 24 & MSDM & & \\
\hline 25 & Pemasaran & SKB & \\
\hline 26 & Pemasaran & MSDM & SKB \\
\hline 27 & SKB & Pemasaran & \\
\hline 28 & MSDM & SKB & Pemasaran \\
\hline 29 & Pemasaran & SKB & MSDM \\
\hline 30 & MSDM & Pemasaran & \\
\hline 31 & SKB & MSDM & \\
\hline 32 & Pemasaran & MSDM & SKB \\
\hline 33 & Pemasaran & MSDM & SKB \\
\hline 34 & MSDM & SKB & Pemasaran \\
\hline 35 & Pemasaran & SKB & MSDM \\
\hline 36 & MSDM & Pemasaran & \\
\hline 37 & SKB & MSDM & \\
\hline
\end{tabular}

\begin{tabular}{|c|l|l|l|}
\hline Mhs & \multicolumn{1}{|c|}{ MK1 } & \multicolumn{1}{|c|}{ MK2 } & \multicolumn{1}{|c|}{} \\
\hline 38 & Pemasaran & MSDM & SKB \\
\hline 39 & Pemasaran & MSDM & SKB \\
\hline 40 & SKB & Pemasaran & MSDM \\
\hline 41 & MSDM & & \\
\hline 42 & Pemasaran & SKB & \\
\hline 43 & Pemasaran & MSDM & SKB \\
\hline 44 & SKB & Pemasaran & \\
\hline 45 & SKB & MSDM & \\
\hline 46 & Pemasaran & MSDM & SKB \\
\hline 47 & Pemasaran & MSDM & SKB \\
\hline 48 & SKB & Pemasaran & MSDM \\
\hline 49 & MSDM & & \\
\hline 50 & Pemasaran & SKB & \\
\hline
\end{tabular}

\section{Analisis Frekuensi Tinggi}

Tahapan ini mencari kombinasi item yang memenuhi syarat minimum dari nilai support dalam database. Nilai support sebuah item diperoleh dengan rumus berikut:

Support $(A)=(1)$

Sedangkan nilai support dari 2 item diperoleh dari rumus berikut:

Support $(A, B)=P(A \cap B)$

Support $(A, B)=$

\section{Melakukan Proses}

Berdasarkan variabel-variabel data mata kuliah di atas, maka format data dapat dilihat pada tabel berikut ini:

Tabel 2. Kombinasi Data Mata Kuliah

\begin{tabular}{|c|c|}
\hline Kombinasi & Jumlah \\
\hline Pemasaran, SKB & 7 \\
\hline
\end{tabular}




\begin{tabular}{|l|c|}
\hline MSDM, Pemasaran & 4 \\
\hline SKB, MSDM & 5 \\
\hline
\end{tabular}

Setelah data diperoleh, selanjutnya adalah mengelompokkan mahasiswa berdasarkan mata kuliah yang dipilih sebagaimana tabel berikut.

Tabel 3. Data Mata Kuliah Pilihan per Mahasiswa

\begin{tabular}{|c|l|}
\hline Mhs & \multicolumn{1}{|c|}{ Mata Kuliah } \\
\hline 1 & SKB, Pemasaran, MSDM \\
\hline 2 & MSDM \\
\hline 3 & Pemasaran, SKB \\
\hline 4 & Pemasaran, SKB, MSDM \\
\hline 5 & SKB, Pemasaran \\
\hline 6 & MSDM, SKB, Pemasaran \\
\hline 7 & Pemasaran, SKB, MSDM \\
\hline 8 & MSDM, Pemasaran \\
\hline 9 & SKB, MSDM \\
\hline 10 & Pemasaran, MSDM, SKB \\
\hline 11 & Pemasaran, MSDM, SKB \\
\hline 12 & SKB, Pemasaran \\
\hline 13 & MSDM, SKB, Pemasaran \\
\hline 14 & Pemasaran, SKB, MSDM \\
\hline 15 & MSDM, Pemasaran \\
\hline 16 & SKB, Pemasaran \\
\hline 17 & MSDM, SKB, Pemasaran \\
\hline 18 & Pemasaran, SKB, MSDM \\
\hline 19 & MSDM, Pemasaran \\
\hline 20 & SKB, MSDM \\
\hline 1
\end{tabular}

\begin{tabular}{|c|c|}
\hline Mhs & Mata Kuliah \\
\hline 21 & Pemasaran, MSDM, SKB \\
\hline 22 & Pemasaran, MSDM, SKB \\
\hline 23 & SKB, Pemasaran, MSDM \\
\hline 24 & MSDM \\
\hline 25 & Pemasaran, SKB \\
\hline 26 & Pemasaran, MSDM, SKB \\
\hline 27 & SKB, Pemasaran \\
\hline 28 & MSDM, SKB, Pemasaran \\
\hline 29 & Pemasaran, SKB, MSDM \\
\hline 30 & MSDM, Pemasaran \\
\hline 31 & SKB, MSDM \\
\hline 32 & Pemasaran, MSDM, SKB \\
\hline 33 & Pemasaran, MSDM, SKB \\
\hline 34 & MSDM, SKB, Pemasaran \\
\hline 35 & Pemasaran, SKB, MSDM \\
\hline 36 & MSDM, Pemasaran \\
\hline 37 & SKB, MSDM \\
\hline 38 & Pemasaran, MSDM, SKB \\
\hline 39 & Pemasaran, MSDM, SKB \\
\hline 40 & SKB, Pemasaran, MSDM \\
\hline 41 & MSDM \\
\hline 42 & Pemasaran, SKB \\
\hline 43 & Pemasaran, MSDM, SKB \\
\hline 44 & SKB, Pemasaran \\
\hline 45 & SKB, MSDM \\
\hline 46 & Pemasaran, MSDM, SKB \\
\hline
\end{tabular}




\begin{tabular}{|c|l|}
\hline Mhs & \multicolumn{1}{|c|}{ Mata Kuliah } \\
\hline 47 & Pemasaran, MSDM, SKB \\
\hline 48 & SKB, Pemasaran, MSDM \\
\hline 49 & MSDM \\
\hline 50 & Pemasaran, SKB \\
\hline
\end{tabular}

Data transaksional di atas lalu direpresentasikan dalam bentuk seperti terlihat pada tabel berikut ini:

Tabel 4. Representasi Data Mata Kuliah

\begin{tabular}{|c|l|}
\hline Mhs & \multicolumn{1}{|c|}{ Mata Kuliah } \\
\hline 1 & SKB \\
\hline 1 & Pemasaran \\
\hline 1 & MSDM \\
\hline 2 & MSDM \\
\hline 3 & Pemasaran \\
\hline 3 & SKB \\
\hline 4 & Pemasaran \\
\hline 4 & SKB \\
\hline 4 & MSDM \\
\hline 5 & SKB \\
\hline 5 & Pemasaran \\
\hline 6 & MSDM \\
\hline 6 & SKB \\
\hline 6 & Pemasaran \\
\hline 7 & Pemasaran \\
\hline 7 & SKB \\
\hline 7 & MSDM \\
\hline
\end{tabular}

\begin{tabular}{|c|c|}
\hline Mhs & Mata Kuliah \\
\hline 8 & MSDM \\
\hline 8 & Pemasaran \\
\hline 9 & SKB \\
\hline 9 & MSDM \\
\hline 10 & Pemasaran \\
\hline 10 & MSDM \\
\hline 10 & SKB \\
\hline 11 & Pemasaran \\
\hline 11 & MSDM \\
\hline 11 & SKB \\
\hline 12 & SKB \\
\hline 12 & Pemasaran \\
\hline 13 & MSDM \\
\hline 13 & SKB \\
\hline 13 & Pemasaran \\
\hline 14 & Pemasaran \\
\hline 14 & SKB \\
\hline 14 & MSDM \\
\hline 15 & MSDM \\
\hline 15 & Pemasaran \\
\hline 16 & SKB \\
\hline 16 & Pemasaran \\
\hline 17 & MSDM \\
\hline 17 & SKB \\
\hline 17 & Pemasaran \\
\hline 18 & Pemasaran \\
\hline
\end{tabular}




\begin{tabular}{|c|c|}
\hline Mhs & Mata Kuliah \\
\hline 18 & SKB \\
\hline 18 & MSDM \\
\hline 19 & MSDM \\
\hline 19 & Pemasaran \\
\hline 20 & SKB \\
\hline 20 & MSDM \\
\hline 21 & Pemasaran \\
\hline 21 & MSDM \\
\hline 21 & SKB \\
\hline 22 & Pemasaran \\
\hline 22 & MSDM \\
\hline 22 & SKB \\
\hline 23 & SKB \\
\hline 23 & Pemasaran \\
\hline 23 & MSDM \\
\hline 24 & MSDM \\
\hline 25 & Pemasaran \\
\hline 25 & SKB \\
\hline 26 & Pemasaran \\
\hline 26 & MSDM \\
\hline 26 & SKB \\
\hline 27 & SKB \\
\hline 27 & Pemasaran \\
\hline 28 & MSDM \\
\hline 28 & SKB \\
\hline 28 & Pemasaran \\
\hline
\end{tabular}

\begin{tabular}{|c|c|}
\hline Mhs & Mata Kuliah \\
\hline 29 & Pemasaran \\
\hline 29 & MSDM \\
\hline 29 & SKB \\
\hline 30 & MSDM \\
\hline 30 & Pemasaran \\
\hline 31 & SKB \\
\hline 31 & MSDM \\
\hline 32 & Pemasaran \\
\hline 32 & MSDM \\
\hline 32 & SKB \\
\hline 33 & Pemasaran \\
\hline 33 & SKB \\
\hline 33 & MSDM \\
\hline 34 & MSDM \\
\hline 34 & SKB \\
\hline 34 & Pemasaran \\
\hline 35 & Pemasaran \\
\hline 35 & SKB \\
\hline 35 & MSDM \\
\hline 36 & MSDM \\
\hline 36 & Pemasaran \\
\hline 37 & SKB \\
\hline 37 & MSDM \\
\hline 38 & Pemasaran \\
\hline 38 & MSDM \\
\hline 38 & SKB \\
\hline
\end{tabular}




\begin{tabular}{|c|c|}
\hline Mhs & Mata Kuliah \\
\hline 39 & Pemasaran \\
\hline 39 & MSDM \\
\hline 39 & SKB \\
\hline 40 & SKB \\
\hline 40 & Pemasaran \\
\hline 40 & MSDM \\
\hline 41 & MSDM \\
\hline 42 & Pemasaran \\
\hline 42 & SKB \\
\hline 43 & Pemasaran \\
\hline 43 & MSDM \\
\hline 43 & SKB \\
\hline 44 & SKB \\
\hline 44 & Pemasaran \\
\hline 45 & SKB \\
\hline 45 & MSDM \\
\hline 46 & Pemasaran \\
\hline 46 & MSDM \\
\hline 46 & SKB \\
\hline 47 & Pemasaran \\
\hline 47 & MSDM \\
\hline 47 & SKB \\
\hline 48 & SKB \\
\hline 48 & Pemasaran \\
\hline 48 & MSDM \\
\hline 49 & MSDM \\
\hline
\end{tabular}

\begin{tabular}{|c|l|}
\hline Mhs & \multicolumn{1}{|c|}{ Mata Kuliah } \\
\hline 50 & Pemasaran \\
\hline 50 & SKB \\
\hline
\end{tabular}

Pada pengujian ini, penulis menetapkan nilai minimum support sebesar 5\% dan minimum confidence sebesar 10\%. Sehingga data yang akan diproses oleh software Orange hanyalah rule-rule yang memenuhi kriteria di atas. Tabel berikut ini menunjukkan calon 2itemset dari data mata kuliah pilihan yang memenuhi ketentuan minimum support dan minimum confidence berdasarkan pada tabel 5 .

Tabel 5. Calon 2-itemset

\begin{tabular}{|l|c|c|}
\hline \multicolumn{1}{|c|}{ Aturan } & Supp & Conf \\
\hline $\begin{array}{l}\text { Jika mengambil mata } \\
\text { kuliah Pemasaran, maka } \\
\text { mengambil mata kuliah } \\
\text { SKB. }\end{array}$ & $14 \%$ & $18 \%$ \\
\hline $\begin{array}{l}\text { Jika mengambil mata } \\
\text { kuliah MSDM, maka } \\
\text { mengambil mata kuliah } \\
\text { Pemasaran. }\end{array}$ & $8 \%$ & $9 \%$ \\
\hline $\begin{array}{l}\text { Jika mengambil mata } \\
\text { kuliah SKB, maka } \\
\text { mengambil mata kuliah } \\
\text { MSDM. }\end{array}$ & $1 \%$ & $12 \%$ \\
\hline
\end{tabular}

Pada Tabel 5, dapat disimpulkan jika ditetapkan nilai dari threshold di mana $\Phi$ $=2$, maka:

$\mathrm{F}_{2}=\{($ Pemasaran, SKB $), \quad(\mathrm{MSDM}$, Pemasaran), (SKB, MSDM) \}.

Kombinasi dari itemset dalam $\mathrm{F}_{2}$ dapat kita gabungkan menjadi calon 3 itemset. Itemset-itemset dari $\mathrm{F}_{2}$ yang dapat digabungkan adalah itemset-itemset yang memiliki kesamaan dalam $k-1$ item pertama. Calon 3-itemset yang dapat dibentuk dari $\mathrm{F}_{2}$ tampak pada tabel 6 . Dengan demikian $\mathrm{F}_{3}=\{(\mathrm{SKB}$, 
Pemasaran, MSDM), (Pemasaran, SKB, MSDM), (MSDM, SKB, Pemasaran), (Pemasaran, MSDM, SKB) \}.

Tabel 6. Calon 3-itemset

\begin{tabular}{|l|c|c|}
\hline \multicolumn{1}{|c|}{ Aturan } & Sup & Conf \\
\hline $\begin{array}{l}\text { Jika mengambil mata } \\
\text { kuliah SKB dan } \\
\text { Pemasaran, maka } \\
\text { mengambil mata kuliah } \\
\text { MSDM. }\end{array}$ & $6 \%$ & $42 \%$ \\
\hline $\begin{array}{l}\text { Jika mengambil mata } \\
\text { kuliah Pemasaran dan } \\
\text { SKB, maka mengambil } \\
\text { mata kuliah MSDM }\end{array}$ & $12 \%$ & $85 \%$ \\
\hline $\begin{array}{l}\text { Jika mengambil mata } \\
\text { kuliah MSDM dan SKB, } \\
\text { maka mengambil mata } \\
\text { kuliah Pemasaran }\end{array}$ & $1 \%$ & $1 \%$ \\
\hline $\begin{array}{l}\text { Jika mengambil mata } \\
\text { kuliah Pemasaran dan } \\
\text { MSDM, maka mengambil } \\
\text { mata kuliah SKB }\end{array}$ & $2 \%$ & $25 \%$ \\
\hline
\end{tabular}

\section{Pembentukan Aturan Asosiasi}

Setelah semua pola frekuensi tinggi ditemukan, barulah dicari aturan asosiasi yang memenuhi syarat minimum untuk confidence dengan menghitung confidence aturan asosiasi $\mathrm{A} \rightarrow \mathrm{B}$. Nilai confidence dari aturan $\mathrm{A} \rightarrow \mathrm{B}$ diperoleh dari rumus berikut.

$$
\text { Confidence }=P(\mathrm{~B} \mid \mathrm{A})
$$

Jika mengambil mata kuliah SKB dan Pemasaran, maka juga mengambil mata kuliah MSDM. Untuk mendapatkan nilai support dari aturan ini maka masukkan nilai total total judul yang mengandung SKB, Pemasaran dan MSDM lalu dibagi dengan total mata kuliah pilihan. Rujukan dari rumus ini adalah pada tabel 6 dengan 3-itemset dan tabel 5 dengan 2-itemset. Sementara untuk mendapatkan nilai confidence dari aturan ini adalah dengan menghitung total pengambilan mata kuliah mengandung SKB, Pemasaran dan MSDM lalu dibagi dengan total pengambilan mata kuliah yang mengandung SKB dan Pemasaran.

Tabel 5 di atas dapat disimpulkan nilai support dan confidence dengan acuan 2-itemset yang memiliki nilai tertinggi adalah kombinasi antara Pemasaran dan SKB dengan support $14 \%$ dan confidence $18 \%$.

Tabel 6 di atas diperoleh 4 aturan asosiasi yang memenuhi syarat minimum support dan minimum confidence. Dapat pula disimpulkan bahwa semua kombinasi mata kuliah Pemasaran, SKB dan MSDM memiliki nilai tertinggi yaitu support $12 \%$ dan confidence $85 \%$.

\section{Hasil Pengujian pada Software}

Pengujian terhadap hasil analisa, sangat penting dilakukan untuk menentukan dan memastikan apakah hasil analisa tersebut benar atau tidak. Software yang penulis gunakan dalam pengujian ini adalah Orange.

Tahapan dalam pengujian pada Orange adalah sebagai berikut:

a. Aktifkan software Orange sehingga tampil gambar berikut.

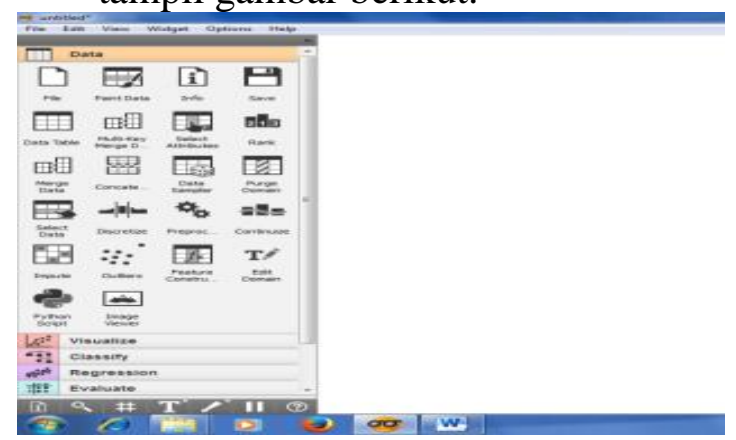

Gambar 2. Area Kerja pada Orange

b. Setelah jendela Orange terbuka, klik menu File, klik kanan lalu pilih Open untuk membuka file daftar pengajuan judul pada office Excel seperti gambar berikut. 


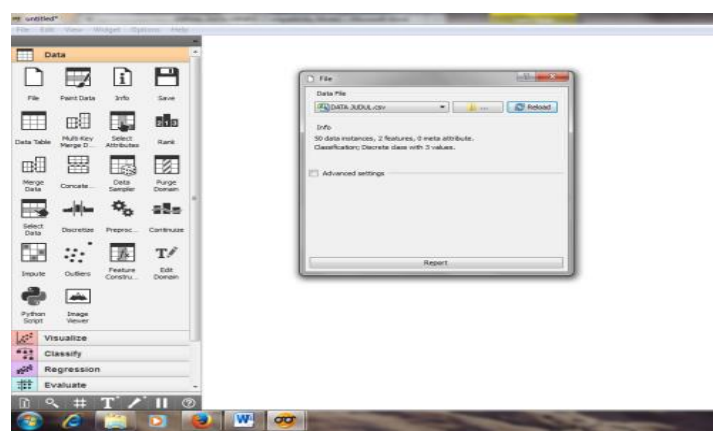

Gambar 3. Proses Pemanggilan Data

c. Langkah berikutnya adalah melakukan pengecekan apakah data terbaca pada Orange, caranya dengan mengklik menu Data Table tepat di bawah menu File, hubungkan menu File dan Data Table lalu klik kanan dan pilih Open pada Data Table untuk melihat tabel mata kuliah pilihan seperti gambar berikut.

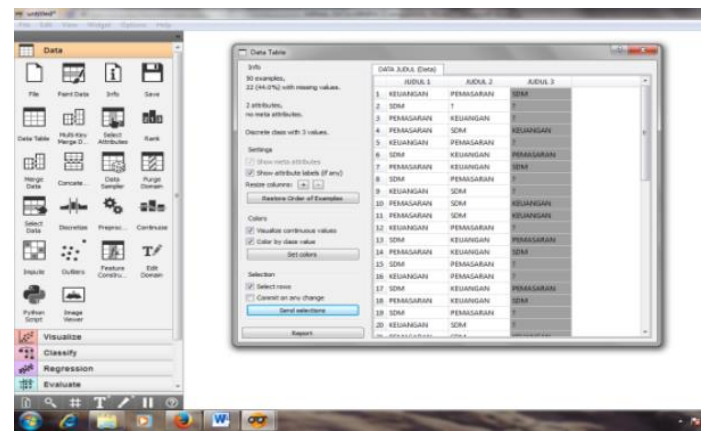

Gambar 4. Daftar Mata Kuliah Pilihan Pada Orange

d. Langkah berikutnya adalah memasukkan menu Association Rules, hubungkan menu File dengan Association Rules, klik kanan Open, lalu atur ukuran Minimum Support $5 \%$ \& Minimum Confidence 10\% seperti gambar 5 .

e. Selanjutnya masukkan menu Association Rules Explorer, hubungkan menu Association Rules dengan Association Rules Explorer, klik kanan lalu pilih Open untuk melihat Rules yang memenuhi Minimum Support dan Minimum Confidence seperti gambar 6.

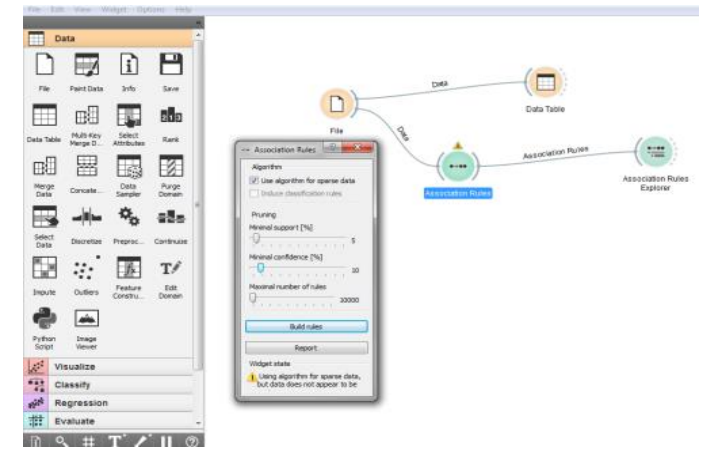

Gambar 5. Pengaturan Support dan Confidence

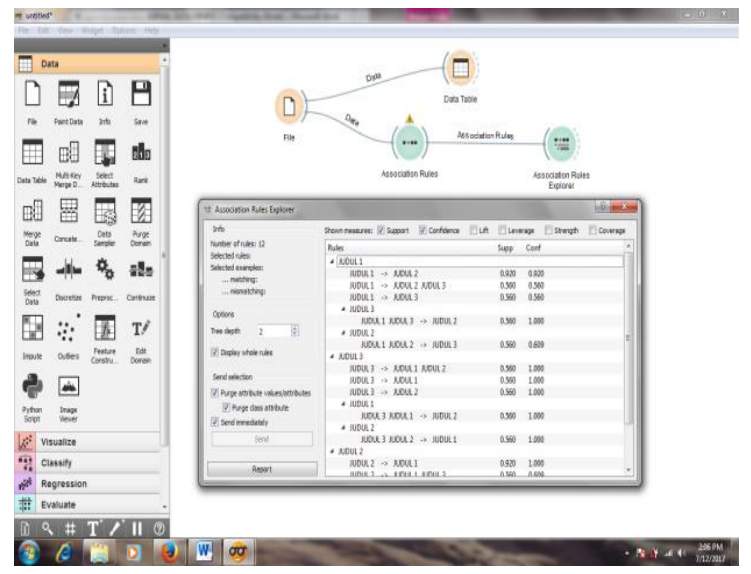

Gambar 6. Hasil Akhir Rule Asosiasi

\section{KESIMPULAN}

Simpulan

Dari uraian di atas dapat ditarik kesimpulan:

a. Nilai support dan confidence dengan acuan 2-itemset yang memiliki nilai tertinggi adalah kombinasi antara mata kuliah Pemasaran dan SKB dengan support $14 \%$ dan confidence $18 \%$.

b. Diperoleh 4 aturan asosiasi yang memenuhi syarat minimum support dan minimum confidence. Kombinasi mata kuliah Pemasaran, SKB dan MSDM memiliki nilai tertinggi yaitu support $12 \%$ dan confidence $85 \%$.

\section{Saran}

Berdasarkan pembahasan di atas, saran penulis sebagai berikut: 
a. Mata kuliah yang banyak dipilih oleh mahasiswa, agar ditingkatkan kualitas dosennya.

b. Mata kuliah yang kurang diminati oleh mahasiswa, agar ditinjau ulang pada kurikulum.

c. Lakukan analisis secara berkelanjutan terhadap mata kuliah yang telah dipilih oleh mahasiswa.

\section{DAFTAR PUSTAKA}

Anas, A. (2015). Algorithm Apriori Use For A Consumer Behavior In. Sains Dan Informatika, 1, 45-59.

Choiriah, W. (2016). Penggunaan Algorithma Apriori Data Mining Untuk Mengetahui Tingkatkesetiaan Konsumen ( Brand Loyality ) Terhadap Merek Kenderaan Bermotor ( Studi Kasus Dealer Honda Rumbai ), $x(\mathrm{x}), 44-52$.

Emha Taufiq Luthfi. (2009). Penerapan Data Mining Algoritma Asosiasi Untuk Meningkatkan Penjualan. Seminar Nasional Aplikasi Sains \& Teknologi (SNAST) Periode III, 10(1), 1-21.

Erwin. (2009). Analisis Market Basket Dengan Algoritma. Jurnal Generic, 4, 26-30.

Pane, D. K. (2013). Implementasi Data Mining Pada Penjualan Produk Elektronik Dengan Algoritma Apriori ( Studi Kasus : Kreditplus ). Pelita Informatika Budi Darma, 2529.

Siregar, S. R. (2014). Implementasi Data Mining Pada Penjualan Tiket Pesawat Menggunakan Algoritma
Apriori ( Studi Kasus: Jumbo Travel Medan ). Pelita Informatika Budi Darma, Volume Vii, Nomor 1, Juli 2014, VII, 152-156.

Tampubolon, K., Saragih, H., Reza, B., Epicentrum, K., Asosiasi, A., \& Apriori, A. (2013). Implementasi Data Mining Algoritma Apriori Pada Sistem Persediaan Alat-Alat Kesehatan. Informasi Dan Teknologi Ilmiah, 93-106. https://doi.org/2339-210X

Wandi, N., Hendrawan, R. A., \& Mukhlason, A. (2012). Pengembangan Sistem Rekomendasi Penelusuran Buku dengan Penggalian Association Rule Menggunakan Algoritma Apriori. Jurnal Teknik ITS, 1, 1-5. https://doi.org/10.12962/j23373539. v1i1.1293

Widiati, E., \& Evita Dewi, K. (2014). Implementasi Association Rule Terhadap Penyusunan Layout Makanan Dan Penentuan Paket Makanan Hemat Di RM Roso Echo Dengan Algoritma Apriori. Jurnal Ilmiah Komputer Dan Informatika (KOMPUTA), 96(2), 2089-9033.

Widodo. (2008). Prediksi Mata Kuliah Pilihan dengan Aturan Asosiasi Widodo. Science, 2008, 21-23.

Yanto, R., \& Khoiriah, R. (2015). Implementasi Data Mining dengan Metode Algoritma Apriori dalam Menentukan Pola Pembelian Obat. Creative Information Technology Journal, 2(2), 102-113. https://doi.org/2354-5771 